\title{
Pellicle formation in Shewanella oneidensis
}

\author{
Yili Liang ${ }^{1,2}$, Haichun Gao ${ }^{2,3^{*}}$, Jingrong Chen², Yangyang Dong ${ }^{3}$, Lin $\mathrm{Wu}^{3}$, Zhili He', Xueduan Liu', Guanzhou Qiu', \\ Jizhong Zhou ${ }^{1,2^{*}}$
}

\begin{abstract}
Background: Although solid surface-associated biofilm development of S. oneidensis has been extensively studied in recent years, pellicles formed at the air-liquid interface are largely overlooked. The goal of this work was to understand basic requirements and mechanism of pellicle formation in S. oneidensis.

Results: We demonstrated that pellicle formation can be completed when oxygen and certain cations were present. $\mathrm{Ca}(\mathrm{II}), \mathrm{Mn}(\mathrm{II}), \mathrm{Cu}(\mathrm{II})$, and $\mathrm{Zn}(\mathrm{II})$ were essential for the process evidenced by fully rescuing pellicle formation of S. oneidensis from the EDTA treatment while Mg (II), Fe(II), and Fe(III) were much less effective. Proteins rather than DNA were crucial in pellicle formation and the major exopolysaccharides may be rich in mannose. Mutational analysis revealed that flagella were not required for pellicle formation but flagellum-less mutants delayed pellicle development substantially, likely due to reduced growth in static media. The analysis also demonstrated that AggA type I secretion system was essential in formation of pellicles but not of solid surface-associated biofilms in $S$. oneidensis.

Conclusion: This systematic characterization of pellicle formation shed lights on our understanding of biofilm formation in S. oneidensis and indicated that the pellicle may serve as a good research model for studying bacterial communities.
\end{abstract}

\section{Background}

Most microbes in natural ecosystems exist in highly organized and functional interactive communities, which are composed of cells attached to surfaces and/or to each other either from a single species or multiple species [1-7]. Microbial communities confer a number of advantages for survival, such as nutrient availability with metabolic cooperation, acquisition of new genetic traits, and protection from the environment $[4,8]$. The most common microbial communities are biofilms, which refer to assemblages of cell on solid biotic or abiotic surfaces. In recent years, the subject of microbial biofilms has drawn a lot of attention and numerous studies have provided important insights into the genetic basis of biofilm development [5,7].

Pellicles, arising from the interface between air and liquid and therefore frequently called air-liquid (A-L) biofilms [9], have been well studied in an array of

\footnotetext{
* Correspondence: haichung@zju.edu.cn; jzhou@ou.edu

${ }^{1}$ School of Minerals processing and Bioengineering, Central south University, Changsha, 410083, PR China

${ }^{2}$ Institute for Environmental Genomics and Department of Botany and

Microbiology, University of Oklahoma, Norman, 73019, USA

Full list of author information is available at the end of the article
}

bacteria, such as Bacillus subtilis, Pseudomonas aeruginosa, and Vibrio parahaemolyticus [7,10-12]. Pellicle formation consists of at least three distinctive steps: (i) initial attachment of bacteria to the solid surface (wall of culture device) at the interface between air and liquid, (ii) development of the monolayer pellicle initiated from the attached cells, and (iii) maturation of pellicles with characteristic three-dimensional architecture [1,11]. In addition to cells, a variety of components, mainly extracellular polymeric substances (EPS), are needed for developing and maintaining the pellicle matrix. The most extensively studied EPS include exopolysaccharides, proteins, and extracellular DNA although contributions of these agents to the integrity of the pellicle matrix may vary [11]. While the pellicle is generally taken into account as a special form of biofilms [5,7,13], its distinguishing characteristics justify that this type of biofilm may serve as an independent research model [12-14].

Many factors, including extracellular organelles such as flagella and type IV pili, secreted proteins, and chemical agents supplemented in media such as iron and phosphate, have been shown to play important roles in 
biofilm formation [5]. However, effects of these factors on the biofilm formation process depend on the bacterium under study. For example, flagella facilitate surface adhesion for many species but it has been also observed in other species that mutations resulting in aflagellate and paralyzed nonmotile cells promote formation of a multilayer biofilm [7]. In the case of iron, results are even more inconsistent. In P. aeruginosa and Vibrio cholerae, iron limitation hinders biofilm formation whereas it facilitates the process in Actinomyces naeslundii and Staphylococcus epidermidis $[15,16]$. It has been suggested that variation in effects of these factors on biofilm formation by particular species of bacteria may be reflection of the different environmental niches where they live [14,17-19].

Shewanella oneidensis MR-1, a facultative Gram-negative anaerobe with a remarkable respiratory versatility, has been extensively studied for its biofilm development [20-26]. However, little progress has been made to understand biological mechanisms of pellicle formation. This work represents the initial steps in characterizing the process in S. oneidensis. We showed that successful pellicle formation required the availability of oxygen and the presence of certain metal cations. A further analysis on metal cations revealed that $\mathrm{Fe}(\mathrm{II})$ and $\mathrm{Fe}(\mathrm{III})$ were not as essential as $\mathrm{Ca}(\mathrm{II}), \mathrm{Cu}(\mathrm{II}), \mathrm{Mn}(\mathrm{II})$, and $\mathrm{Zn}(\mathrm{II})$ for pellicle formation. In addition, results presented demonstrated that a type I secretion pathway of S. oneidensis is required for the pellicle development but not for attachment to abiotic surface.

\section{Results}

Characteristics of $S$. oneidensis growth in still media under aerobic conditions

The $S$. oneidensis MR-1 cells grew rapidly in LB in a flask when aeration of the media was provided by vigorously shaking, with a doubling time of approximately 40 $\mathrm{min}$ at the room temperature (Figure 1A). Such growth eventually led to formation of the solid surface-associated (SSA) biofilms on the flask wall, especially around the A-L interface. Cells in static media accessible to ambient air, however, displayed a different growth pattern. Before pellicles were formed, cells lived in the planktonic form with a much longer doubling time, approximately $2.6 \mathrm{~h}$ (Figure 1A). Once pellicle formation initiated, some of the planktonic cells started to form pellicles while the rest remained in the planktonic form. During the development of pellicles, the planktonic cells grew at a much lower rate with a doubling time of approximately $6 \mathrm{~h}$ (Figure 1A). In this study, initiation of pellicle formation was determined by the time point where the growth rate of the planktonic cells changed although pellicles visible to naked eyes appeared much later, about 12 hours after inoculation at the room temperature. Both complex and defined media supported pellicle formation of $S$. oneidensis. However, pellicles from LB were thick and fairly uniform compared to thin and porous ones from the defined medium, indicating an impact of nutrition on pellicle formation (Figure 1B). We therefore chose LB through the rest of this study unless otherwise noted.

\section{Oxygen is required for pellicle formation in S. oneidensis}

As demonstrated above, $S$. oneidensis initiated the pellicle formation process under aerobic conditions. We then asked whether oxygen is an essential factor for pellicle formation of this microorganism. The pellicle formation assay was carried out under anaerobic conditions with lactate as the electron donor and one of following agents as the electron acceptors: fumarate $(20 \mathrm{mM})$, nitrate $(5 \mathrm{mM})$, DMSO $(20 \mathrm{mM})$, TMAO (20 $\mathrm{mM})$, or ferrous citrate $(10 \mathrm{mM})$. In all cases, the capacity of $S$. oneidensis cells to form pellicles was abolished (data not shown), indicating that oxygen is required for the process. This is in agreement with the findings that the lack of oxygen also resulted in a defect in SSA biofilm formation and a sudden decrease in oxygen concentration led to rapid detachment of SSA biofilms [25,27].

To further elucidate the role of oxygen in pellicle formation, dissolved oxygen concentrations (DOC) at four different depths below the surface in the unshaken cultures were measured in a time-course manner. Results revealed that $\mathrm{DOC}$ at $0.5,1$, and $2 \mathrm{~cm}$ below the surface in the unshaken cultures displayed a similar declining pattern with time, decreased rapidly from approximately 8 to $0.04 \mathrm{mg} / \mathrm{L}$ during the first two and half hours, and then remained stable at $0.04 \mathrm{mg} / \mathrm{L}$ (Figure $1 \mathrm{C}$ ). However, DOC at the depth immediately below the surface $(0.1 \mathrm{~cm}$ but the detector immersed in the liquid) reduced in a much slower rate and reached the lowest level of 0.04 $\mathrm{mg} / \mathrm{L}$ only after the pellicle formed. These data indicate that the majority of dissolved oxygen is likely consumed by the cells close to the surface and the cells below the surface were grown under microaerobic/anaerobic conditions even before the pellicle was formed.

Proteins are essential in pellicle formation of $S$. oneidensis Since EPS, including proteins, polysaccharides, extracellular DNA, humic acid, and sugar, are important in SSA biofilm and pellicle formation of various bacteria, we speculated that these biopolymers may play a role in pellicle formation of $S$. oneidensis. To this end, effects of proteinase $\mathrm{K}$ and DNase I on pellicle formation and developed pellicles were assessed. The pellicles were prevented from formation in the presence of $100 \mu \mathrm{g} / \mathrm{ml}$ proteinase K (Figure 2A). Consistently, $100 \mu \mathrm{g} / \mathrm{ml}$ of the proteinase $\mathrm{K}$ was able to degrade the developed pellicles in $24 \mathrm{~h}$, resulting in the semi-transparent membrane- 


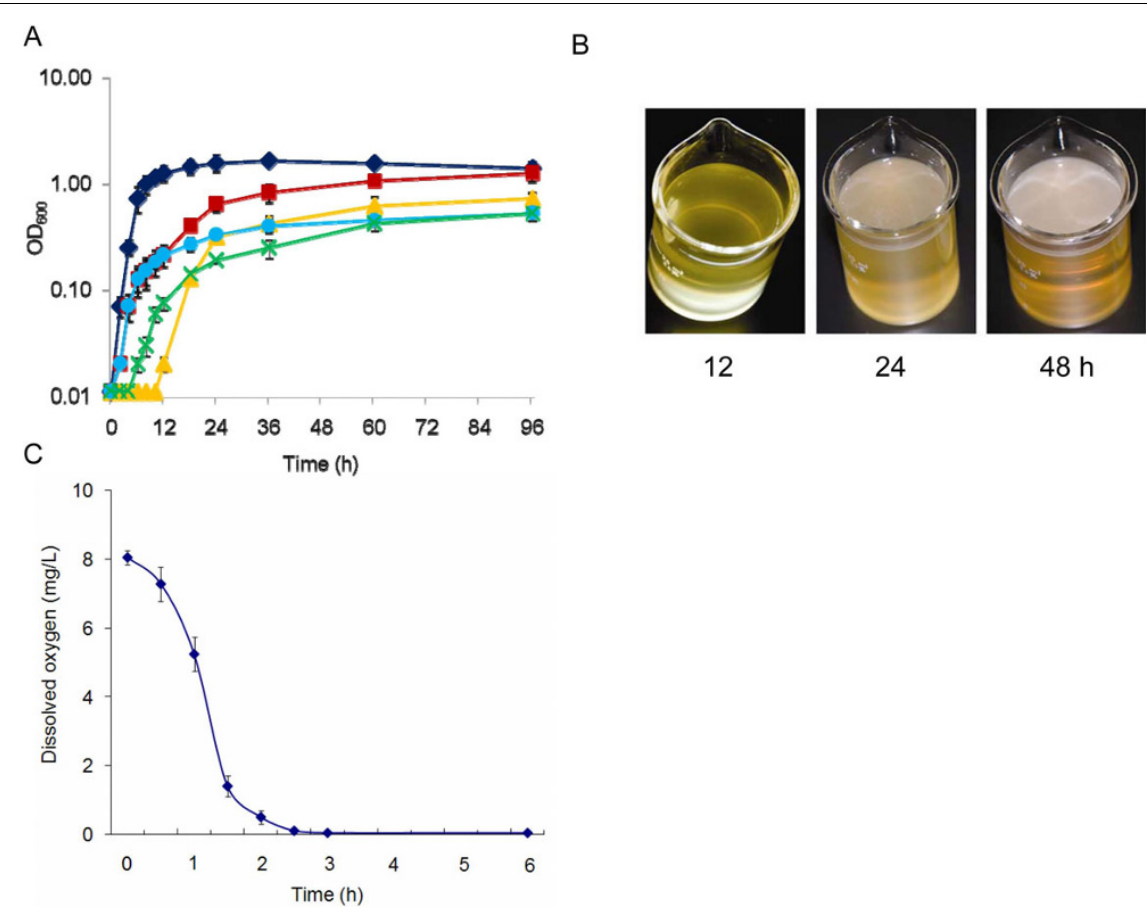

Figure 1 Pellicle formation of S. oneidensis in LB under aerobic conditions. (A) Growth of S. oneidensis in static liquid LB under aerobic conditions. Cell density of all cells (planktonic and pellicle cells combined) (brown square), pellicle cells (yellow triangle), planktonic cells (blue circle), and the $\triangle f l g A$ mutant (green cross) was shown. Growth of agitated cultures (black diamond) is included for comparison. Presented are averages of four replicates with the standard deviation indicated by error bars. (B) Pellicle formation of MR- 1 in static liquid LB under aerobic conditions. The pellicles started to form about $12 \mathrm{~h}$ after inoculation based on the altered growth rate of planktonic cells at the room temperature. (C) Dissolved oxygen concentrations at $1 \mathrm{~cm}$ below the surface in the static MR-1 cultures.

like complexes (Figure 2A). In the control experiment, proteinase $\mathrm{K}$ at concentrations up to $300 \mu \mathrm{g} / \mathrm{ml}$ did not show a noticeable inhibitory influence on growth of S. oneidensis under agitated conditions. On the contrary, DNase I (up to $1000 \mathrm{U} / \mathrm{ml}$ ) was not effective to inhibit pellicle formation or to degrade of the developed pellicles (data not shown), suggesting that DNA plays a negligible role in the process. Since proteinase K unspecifically removes polypeptides in the extracellular space and in the outer-membrane exposed to environments, the results could not conclude whether specific extracellular proteins are required for the process.
A

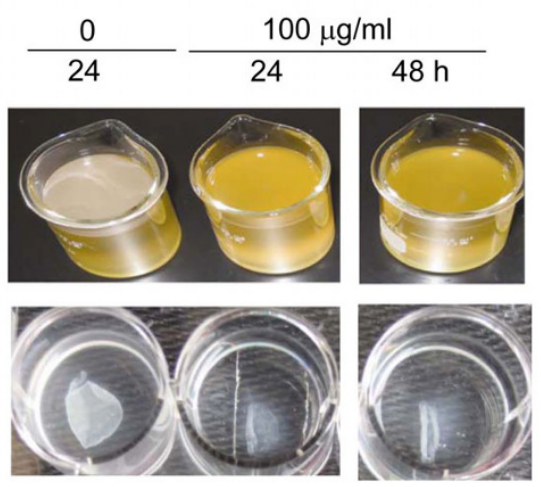

B

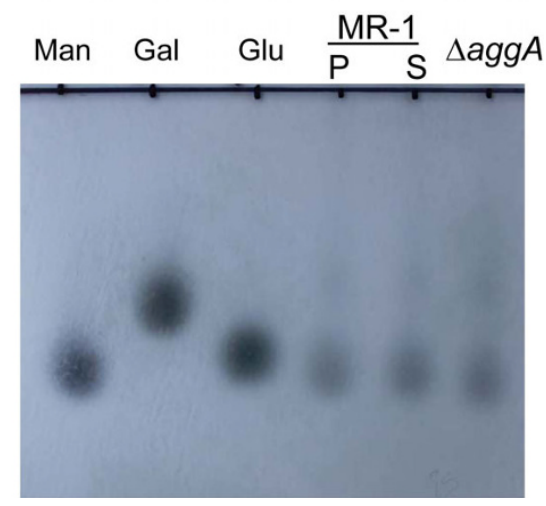

Figure 2 EPS analysis. (A) Effects of proteinase $\mathrm{K}$ on pellicle formation and developed pellicles. Upper-panel, pellicle formation of the WT in static $L B$, in which the proteinase $\mathrm{K}$ was added at inoculation to $100 \mathrm{mg} / \mathrm{ml}$ (final concentration). Lower panel, developed pellicles of the WT (48 $\mathrm{h}$ after inoculation) were treated with $100 \mathrm{mg} / \mathrm{ml}$ (final concentration). (B) TLC analysis of monosaccharide in pellicles and supernatants. $\mathrm{P}$ and $\mathrm{S}$ represent pellicle and supernatant, respectively. Man, gal, and glu represent mannose, galactose, and glucose, respectively. Supernatants of the aggA mutant culture were included in the analysis. 
Attempts were made to solve the major polysaccharide components of $S$. oneidensis pellicles by the thin layer chromatography (TLC) analysis. Culture supernatants and pellicles were collected independently after $36 \mathrm{~h}$ of growth and pellicles were then treated with $100 \mu \mathrm{g} / \mathrm{ml}$ proteinase $\mathrm{K}$ to removed cells. Polysaccharides were extracted and subjected to TLC analysis as described in Methods. A preliminary experiment was performed with six monosaccharides as standards, including ribose, mannose, glucose, galactose, rhamnose, and N-acetylglucosamine. The monosaccharides visualized on the TLC plates were close to mannose, glucose, and galactose (data not shown). To further confirm the observation, the experiment was conducted again with these three monosaccharide standards only. As shown in Figure $2 \mathrm{~B}$ the major monosaccharides identified were most likely to be mannose in both supernatants and pellicles. To validate this result, the $\operatorname{aggA}$ mutant, a pellicle-less strain was included in the analysis and the same result was obtained. These data suggest that the mannose-rich polysaccharides identified in pellicles are not pellicle specific.

\section{Certain metal cations are required for pellicle formation in S. oneidensis}

On the basis that metal cations are of general importance in biofilm formation, we examined the effects of certain metal cations on pellicle formation of S. oneidensis. The metal chelator ethylenediaminetetraacetate (EDTA) has been shown to have an activity against biofilms of various bacteria by removing metal cations $[28,29]$. As shown in Figure 3A, 0.3 mM EDTA completely blocked pellicle formation of $S$. oneidensis. A severe inhibitory effect was also observed in the presence of 0.1 and $0.2 \mathrm{mM}$ of EDTA, reducing the pellicles to approximately 50 and $70 \%$ (by $\mathrm{OD}_{600}$ readings), respectively (Figure 3B). In addition, the pellicle development was much slower than the non-EDTA control. To rule out that the observation was due to toxicity of EDTA to $S$. oneidensis, the same experiment was conducted again under agitated conditions. No noticeable difference in growth between samples containing $0.3 \mathrm{mM}$ EDTA and the non-EDTA control. All these results indicate that EDTA at the tested concentration has a detrimental effect on pellicle formation of $S$. oneidensis.

We reasoned that the inhibitory effect of EDTA on pellicle formation of $S$. oneidensis was due to the absence of free metal cations in the cultures. Therefore, the role of a specific cation in the process can be assessed by the addition of this cation to the cultures containing EDTA. Given that $0.3 \mathrm{mM}$ EDTA appears to be close to the minimal EDTA concentration for complete inhibition of pellicle formation, we chose the concentration for this analysis to determine the importance of a variety of metal cations in pellicle formation. An array of metal cations with different stability constants $\left[\log \left(K^{c}\right)\right]$ were tested, including $\mathrm{Cu}(\mathrm{II})\left[K^{c}=5.77\right], \mathrm{Mg}$ (II) $\left[K^{c}=8.83\right], \mathrm{Ca}(\mathrm{II})\left[K^{c}=10.61\right], \mathrm{Mn}(\mathrm{II})\left[K^{c}=15.6\right]$, $\mathrm{Zn}(\mathrm{II})\left[K^{c}=17.5\right], \mathrm{Fe}(\mathrm{II})\left[K^{c}=25.0\right]$, and Fe(III) $\left[K^{c}=\right.$ 27.2]. To saturate $0.3 \mathrm{mM}$ EDTA, the concentration for each metal cation used was $0.3 \mathrm{mM}$ as well.

The addition of $\mathrm{Ca}(\mathrm{II}), \mathrm{Mn}(\mathrm{II}), \mathrm{Cu}(\mathrm{II})$, or $\mathrm{Zn}$ (II) fully rescued the initiation of pellicle formation at the cell density threshold and subsequent development (Figure $3 \mathrm{~A}$ (only $\mathrm{Ca}(\mathrm{II})$ was shown), 3C). On the contrary, the inhibitory effect of EDTA was noticeably lessened but not fully removed when $\mathrm{Mg}(\mathrm{II})$ was added (Figure $3 \mathrm{~A}$ ). In the case of $\mathrm{Fe}(\mathrm{II})$ and $\mathrm{Fe}(\mathrm{III})$, the addition of either agent partially rescued $(\sim 40 \%)$ the pellicle formation defect caused by EDTA (Figure 3A). In addition, unlike pellicles formed in the non-EDTA control or in the presence of $\mathrm{Ca}(\mathrm{II}), \mathrm{Mn}(\mathrm{II}), \mathrm{Cu}(\mathrm{II})$, or $\mathrm{Zn}(\mathrm{II})$, the Fe-enabled pellicles were weakly attached to the container wall and fragile. As a result, the pellicles can be detached from the wall and broken into pieces with a slight shake. The same results were observed with even higher levels of Fe (II) or Fe(III) (up to $0.9 \mathrm{mM}$ ). In solution, the addition of an extra amount of certain metal cation may release other cations with lower stability constants from EDTA. However, this is unlikely to be the underlying reason for the observed results because the inhibitory effects of these tested cations on pellicle formation are not correlated to the stability constants of the tested metal cations.

\section{Progression of pellicle formation was delayed but not prevented in flagella-less $S$. oneidensis}

Flagella-less and paralyzed flagellar mutants of many motile bacteria are defective in SSA biofilm and pellicle formation because initial surface attachment depends on flagella-mediated motility $[30,31]$. However, reports that biofilm and pellicle formation is not affected or even promoted by mutation resulting in impaired flagella in some other bacteria are not scarce $[1,32,33]$. To assess the role of flagella in pellicle formation of $S$. oneidensis, we tested a flagellum-less strain derived from MR-1 in which $f \lg A$ (so3253) was knocked out. FlgA is a molecular chaperone required for $\mathrm{P}$ ring assembly in the periplasmic space [34]. The mutant was unable to swarm or swim, indicating that the mutation resulted in functionally impaired flagella (Figure 4A). In addition, the flagella were not found on the mutant under an electron microscope (Figure 4A). To confirm this observation, the intact $f l g A$ was cloned into plasmid pBBRMCS-5 for complementation. The ability of the mutant to swarm and swim was restored by the corresponding DNA fragment, indicating that the nonmotile phenotype was due to mutation in the gene (Figure $4 \mathrm{~A}$ ). 
A

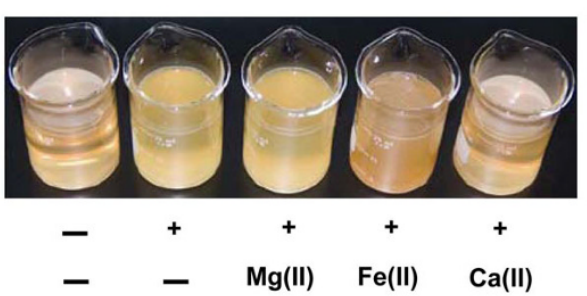

B

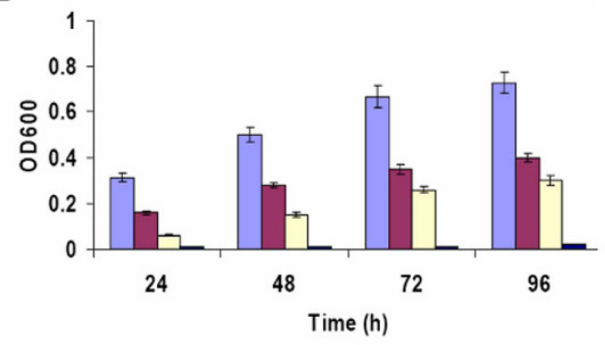

C

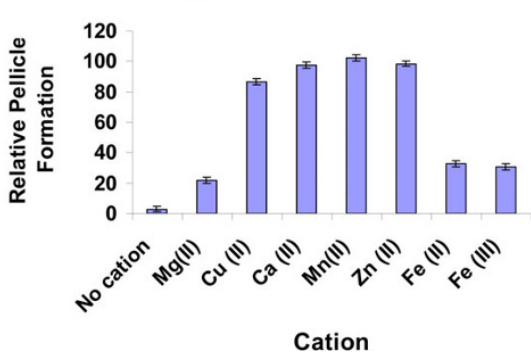

Figure 3 Treatment of $\boldsymbol{S}$. oneidensis pellicles with EDTA and divalent cations. (A) Pellicle formation of the WT after 48 h in static LB in the presence of $0.3 \mathrm{mM}$ EDTA and certain divalent cation $(0.3 \mathrm{mM})$ under aerobic conditions. (B) Cells in pellicles formed in the presence of 0 (light blue), 0.1 (dark red), 0.2 (light yellow), and $0.3 \mathrm{mM}$ (dark blue) EDTA at the different time points. Presented are averages of four replicates with the standard deviation indicated by error bars. (C) Effects of divalent cations on the inhibition of pellicle formation by EDTA. Pellicle formation of the WT after $48 \mathrm{~h}$ in static LB in the presence of $0.3 \mathrm{mM}$ EDTA and one of indicated divalent cations (0.3 mM) under aerobic conditions was shown. The WT in static LB without EDTA was used as the control. The relative pellicle formation ((EDTA and indicated cation)/EDTA-absence control) was presented in the figure. EDTA only ('No cation' was used as the negative control. Presented are averages of four replicates with the standard deviation indicated by error bars.

Compared to MR-1, mutation in $f \lg A$ failed to elicit any significant difference in growth under agitated conditions and SSA biofilm formation (data not shown). However, the mutant displayed a growth defect in the still media and the pellicle formation was drastically delayed. As presented in (Figure 4B), mutation in $f l g A$ resulted in slow growth with a doubling time of $\sim 7 \mathrm{~h}$, approximately 3 times longer than that of the wild type before pellicles were formed (Figure 1A). Once pellicle formation initiated, that did not occur until $30 \mathrm{~h}$ after inoculation, the mutant grew at the rate comparable to the wild type. Interestingly, the development of pellicles in mutants appeared to be normal. As a result, the mutants managed to catch up the wild-type in pellicle production (10 days) (Figure 4B). All of these results suggest that the delayed initiation of pellicle formation of the flgA mutant was possibly due to the slow growth of the mutant cells in the unshaken media and flagella were unlikely to play a significant role in the attachment of $S$. oneidensis cells to the wall or pellicle maturation.

\section{AggA type I secretion pathway is essential in pellicle} formation of S. oneidensis

Previously, a type I secretion system (TISS) consisting of an ATP-binding protein in the inner membrane RtxB (SO4318), an HlyD-family membrane-fusion protein
SO4319, and an agglutination protein AggA (SO4320) was suggested to be important in SSA biofilm formation of $S$. oneidensis $[21,22,35]$. A following mutational analysis revealed that AggA was critical to hyper-aggregation of the COAG strain, a spontaneous mutant from MR-1 [22]. In the case of SSA biofilm formation, the impact of mutation in $\operatorname{aggA}$ was rather mild, reducing the robust biofilm-forming capacity of the COAG strain to the level of the wild-type.

Given the importance of AggA in biofilm formation suggested by above-mentioned studies, it is necessary to assess its role in biofilm formation of $S$. oneidensis with a wild-type genetic background. To this end, we constructed an aggA in-frame deletion mutant with MR-1 as the parental strain. The physiological characterization revealed that the mutant grew at the rate comparable to that of the parental strain either in the shaking or static conditions. However, the $\operatorname{aggA}$ mutant was unable to formed pellicles in 5 days (Figure 5A). Introduction of aggA on plasmid pBBR-AGGA into the mutant restored its ability to form pellicles, verifying that the phenotype of the aggA mutant was specific to the mutation in the $\operatorname{aggA}$ gene (Figure 5A). As a result, the $\operatorname{aggA}$ strain displayed a growth pattern different from the wild type strain in the static media by the lack of the growth rate change which signaled the initiation of pellicle 


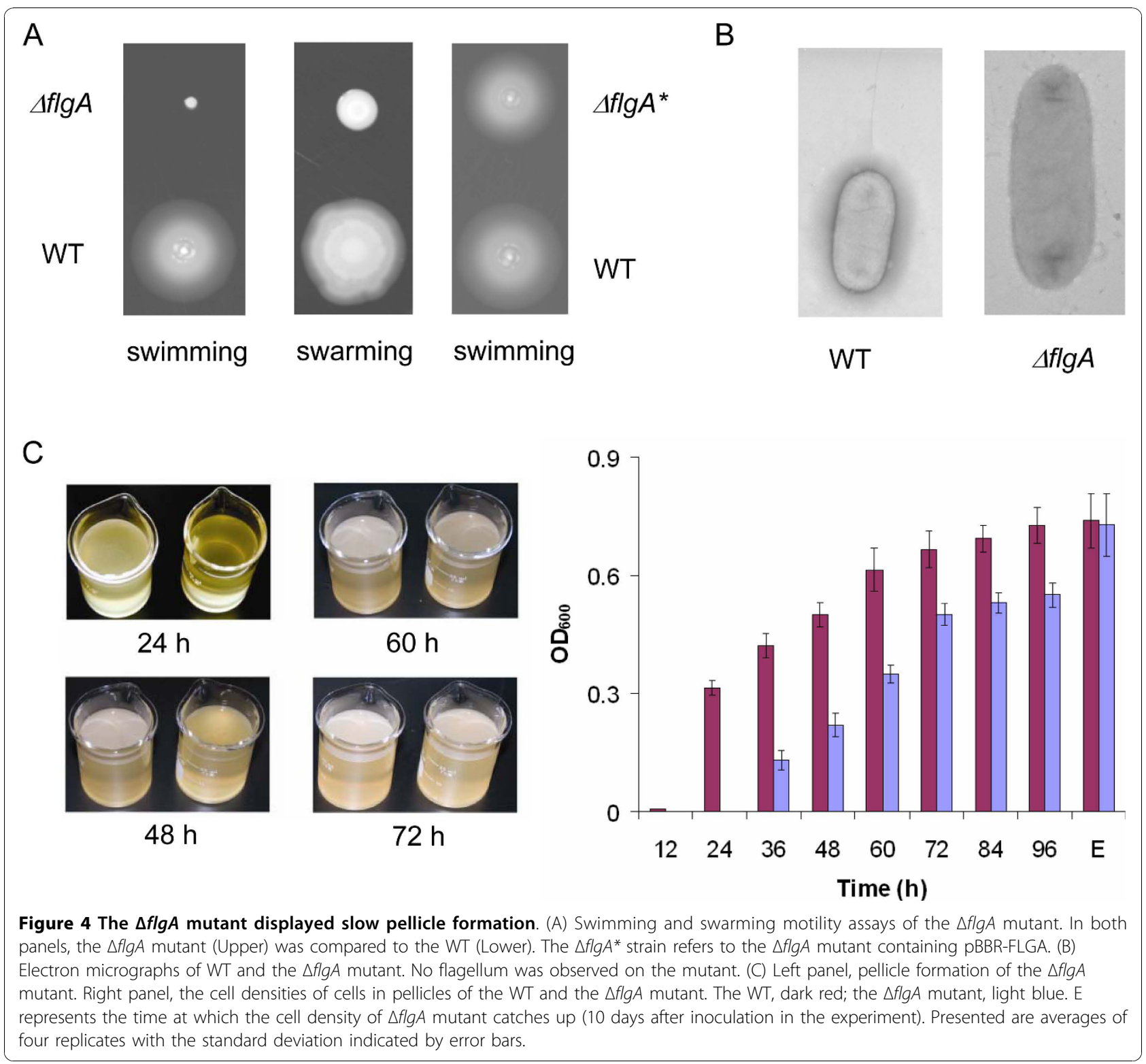

formation (Figure 1A). However, the mutant was able to attach to the glass wall at the air-liquid interface, suggesting that AggA is not essential for this step of biofilm formation (Figure 5A). This proposal gained support from the SSA biofilm formation of the mutant, which differed from that of the wild type strain insignificantly (Figure 5B). All these data implicate that AggA TISS is required for pellicle formation, most likely at the monolayer pellicle formation stage, which appears to be different from that in SSA biofilm formation.

\section{Discussion and Conclusions}

In the microbial world, existence within surface-associated structured multicellular communities is the prevailing lifestyle $[36,37]$. The pellicles of facultative bacteria formed at the liquid-air interface can be selectively advantageous given that respiration with oxygen as the terminal electron acceptor is the most productive. In $S$. oneidensis, the growth rate was promoted by better access to oxygen evidenced by that the cells grew much faster in shaking than in static cultures. Along with the observation that SSA biofilm formation of S. oneidensis was inhibited under anaerobic conditions, the requirement of oxygen for pellicle formation may mainly come from its facilitation of aggregation and attachment of cells to the solid surfaces. This is consistent with previous findings that oxygen promotes autoaggregation of and sudden depletion of molecular oxygen was shown to act as the predominant trigger for initiating detachment of individual cells from biofilms [26,38]. We 


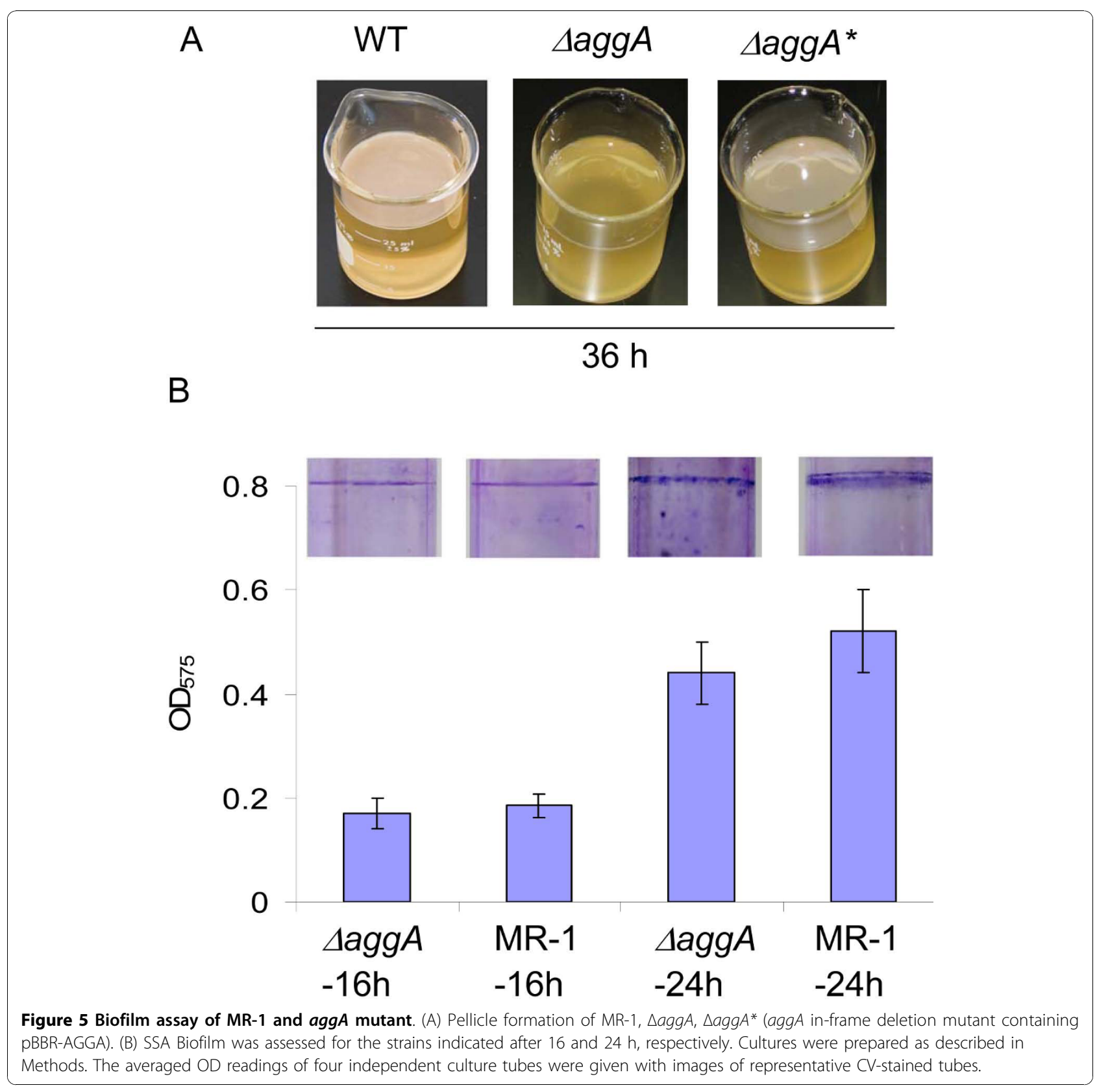

therefore propose that an oxygen gradient established in static cultures with the highest oxygen concentration at the surface resulted in a larger number of cells at the A$\mathrm{L}$ interface to form pellicles, which eventually induce attachment of individual cells to the abiotic surface.

To form pellicles, $S$. oneidensis cultures require certain divalent ions. Involvement of metals in biofilm formation either as a facilitator or an inhibitor has been well documented. In recent years, many elegant studies about the susceptibility of biofilms to metals (as an inhibitor) have been published [39-41]. Although metals as a biofilm formation facilitator have been studied for more than two decades, only a few metals (Ba(II), $\mathrm{Mg}$ (II), $\mathrm{Ca}(\mathrm{II}), \mathrm{Fe}(\mathrm{III})$, and $\mathrm{Fe}(\mathrm{III}))$ have been investigated $[34,42,43]$. In $P$. aeruginosa, all these metals but $\mathrm{Ba}$ (II) are able to protect $P$. aeruginosa biofilms against EDTA treatment, presumably by stabilizing the biofilm matrix. In addition, it has been shown that there is a positive correlation between calcium concentration and amount of biofilm accumulation [44]. While our data support previous conclusions that calcium plays an important role in stabilizing biofilms of bacteria [34,43,44], most of other findings are either new or surprising. Among tested metal cations, $\mathrm{Cu}(\mathrm{II}), \mathrm{Ca}(\mathrm{II}), \mathrm{Mn}(\mathrm{II})$, and $\mathrm{Zn}$ (II) 
belong to the same class, which are capable of restoring the ability of S. oneidensis to form pellicles in the presence of EDTA completely. In contrast, $\mathrm{Mg}$ (II) shows mild effects on relieving EDTA inhibition whereas Fe(II) and $\mathrm{Fe}(\mathrm{III})$ counteracted EDTA in a way different from other tested cations evidenced by the fragile pellicles. In combination, these data suggest that the relative stability constants of metal cations (Cu(II) [5.77], $\mathrm{Mg}$ (II) [8.83], $\mathrm{Ca}(\mathrm{II})$ [10.61], $\mathrm{Mn}$ (II) [15.6], $\mathrm{Zn}$ (II) [17.5], Fe(II) [25.0], and $\mathrm{Fe}(\mathrm{III})[27.2])$ and their affect on EDTA inhibition are not correlated.

It is particularly worth discussing roles of $\mathrm{Fe}(\mathrm{II})$ and $\mathrm{Fe}$ (III) in pellicle formation of S. oneidensis. In recent years, many reports have demonstrated that the iron cations are important, if not essential, in bacterial biofilm formation [34,45-47]. In P. aeruginosa, influence of Fe(II) and $\mathrm{Fe}$ (III) on the process was equivalent to that of $\mathrm{Ca}$ (II) [34]. In S. oneidensis, irons in forms of Fe(II) and Fe(III) were not only unable to neutralize the inhibitory effect of EDTA on pellicle formation completely but also resulted in structurally impaired pellicles although these agents indeed play a role in pellicle formation. This observation indicates that irons are not so crucial as $\mathrm{Cu}(\mathrm{II}), \mathrm{Ca}(\mathrm{II})$, $\mathrm{Mn}(\mathrm{II})$, and $\mathrm{Zn}(\mathrm{II})$ in pellicle formation of $S$. oneidensis. In fact, this may not be surprising. In Acinetobacter baumannii and Staphylococcus aureus, iron limitation improved biofilm formation $[48,49]$. Therefore, it is possible that different bacteria respond to irons in a different way with respect to biofilm formation.

Like SSA biofilms, pellicles require EPS to form a matrix to support embedded cells. Although EPS are now widely recognized as the essential components for biofilm formation and development in all biofilm-forming microorganisms studied so far, diversity in their individual composition and relative abundance of certain elements is substantial [50]. For example, extracellular nucleic acids, which are not important in most biofilmforming microorganisms, are required for SSA biofilm formation in a variety of bacteria $[11,36,37,51,52]$. In $S$. oneidensis, proteins not extracellular DNAs are required to pellicle formation. While essential extracellular proteins for S. oneidensis pellicle formation are largely unknown, results from this study demonstrated that the AggA TISS is crucial in the process, likely at the development of the monolayer. One of substrates of this transporter is predicted to be SO4317, a large 'putative RTX toxin' [35], implicating that the protein may be involved in pellicle formation. In the case of polysaccharides, mannose dominates not only in pellicles but also in supernatants, implicating that mannose-based polysaccharides may have a more general role in the bacterial physiology.

Like in B. subtilis, mutations in S. oneidensis flagellar genes resulting in the nonmotile phenotype significantly delayed the initiation and development of pellicle formation [17]. Here we further illustrated that neither SSA biofilm formation nor the maturization of pellicle was impaired by the mutations. In agreement with findings on biofilm formation of Bacillus cereus [13], this observation suggests that motility not only promotes cells to move to surfaces where the pellicle forms but also facilitate planktonic cells entrance into the pellicle.

Overall, the results presented here provided the first insights into pellicle formation of $S$. oneidensis, making pellicle formation of $S$. oneidensis a simple research model for biofilm formation in general. The study highlights parallels and significant differences between this process and well-documented paradigms, raising some key questions demanding immediate investigations. These include what the major polysaccharides in S. oneidensis pellicles are, why irons result in fragile pellicles in the presence of EDTA, and which proteins and their secretion pathway(s) are directly related to pellicle formation.

\section{Methods}

\section{Bacterial strains, plasmids, and culture conditions}

Bacterial strains and plasmids used in this study are listed in Table 1 [53]. Escherichia coli and S. oneidensis strains were routinely grown in LB broth or on LB plates at $37^{\circ} \mathrm{C}$ and the room temperature for genetic manipulation, respectively. When needed, antibiotics were used at the following concentrations: ampicillin at $50 \mu \mathrm{g} / \mathrm{ml}$ and gentamycin at $15 \mu \mathrm{g} / \mathrm{ml}$.

\section{Pellicle formation, measurement of growth, and quantification of pellicles}

A fresh colony grown overnight on a LB plate was used to inoculate $50 \mathrm{ml} \mathrm{LB}$ and incubated in a shaker $(200$ $\mathrm{rpm})$ to an $\mathrm{OD}_{600}$ of 0.8 at the room temperature. This culture was then diluted 500-fold with fresh LB, resulting in the starting cultures. Throughout the study, all starting cultures of $S$. oneidensis strains were prepared this way. Aliquots of $30 \mathrm{ml}$ starting cultures were transferred to $50 \mathrm{ml}$ Pyrex beakers. The beakers were kept still for pellicle formation at the room temperature and dissolved oxygen (DO) of the cultures was recorded every hour with an Accumet XL40 meter (Fisher Scientific). M1 defined medium containing $0.02 \%(\mathrm{w} / \mathrm{v})$ of vitamin-free Casamino Acids and $15 \mathrm{mM}$ lactate with one of electron acceptors including fumarate $(20 \mathrm{mM})$, nitrate $(5 \mathrm{mM})$, trimethylamine $\mathrm{N}$-oxide (TMAO) $(20$ $\mathrm{mM})$, dimethyl sulfoxide (DMSO) $(20 \mathrm{mM})$ and ferrous citrate $(10 \mathrm{mM})$, was used to test pellicle formation in the defined medium [54]. To separate cells in pellicle and underneath, cultures were withdrawn carefully for collecting planktonic cells and the left pellicles. For growth measurement, 27 parallel starting cultures were 


\begin{tabular}{|c|c|c|}
\hline Strain or plasmid & Relevant genotype & Reference or source \\
\hline \multicolumn{3}{|l|}{ E. coli } \\
\hline WM3064 & Donor strain for conjugation; $\triangle d a p A$ & [53] \\
\hline \multicolumn{3}{|l|}{ S. oneidensis } \\
\hline MR-1 & Wild-type & ATCC 700550 \\
\hline JZ3253 & flgA deletion mutant derived from MR-1; $\triangle$ flgA & This study \\
\hline JZ4320 & aggA deletion mutant derived from MR-1; $\triangle$ aggA & This study \\
\hline \multicolumn{3}{|l|}{ Plasmid } \\
\hline pDS3.0 & $A p^{r}, G m^{r}$, derivative from suicide vector pCVD442 & Lab stock \\
\hline pBBR1MCS-5 & $\mathrm{Gm}^{\mathrm{r}}$ vector used for complementation & Lab Stock \\
\hline pDS-AGGA & aggA deletion construct in pDS3.0 & This study \\
\hline pDS-FLGA & flgA deletion construct in pDS3.0 & This study \\
\hline pBBR-AGGA & pBBR1MCS-5 containing aggA of S. oneidensis & This study \\
\hline pBBR-FLGA & pBBR1MCS-5 containing flgA of S. oneidensis & This study \\
\hline
\end{tabular}

used and 3 were collected at each time point and the rest remained undisturbed. The cell density $\left(\mathrm{OD}_{600}\right)$ of cultures containing planktonic cells was measured first as the planktonic cell density and measured again as the overall cell density after cells from pellicles were added and extensively vortexed. To quantify the pellicles formed by the $S$. oneidensis wild-type and mutant strains, cells from pellicles were collected, suspended in $30 \mathrm{ml}$ fresh LB, violently vortexed, and applied to the spectrometer at $600 \mathrm{~nm}$.

\section{Proteinase $\mathrm{K}$ and DNase I treatment of S. oneidensis pellicles}

$S$. oneidensis was statically cultured in LB broth with the addition of proteinase $\mathrm{K}(0 \mu \mathrm{g} / \mathrm{mL}, 100 \mu \mathrm{g} / \mathrm{mL}$, and 500 $\mu \mathrm{g} / \mathrm{mL}$ ) or DNase I (Qiagen, $0 \mathrm{U} / \mathrm{mL}, 100 \mathrm{U} / \mathrm{mL}, 500 \mathrm{U} /$ $\mathrm{mL}$ and $1000 \mathrm{U} / \mathrm{mL}$ ) for 3 days [55]. We also investigated whether these 3 enzymes could dissolve established pellicles. 2-day old pellicles were rinsed with 20 $\mathrm{mM}$ Tris- $\mathrm{HCl}(\mathrm{pH}=8.0)$ and incubated in the same buffer supplemented with proteinase $\mathrm{K}$ at $37^{\circ} \mathrm{C}$ for 2 days. Similarly, 2-day old pellicles were incubated with DNase I to examine the DNA content at room temperature for 2 days.

\section{Mutagenesis, physiological characterization and complementation of the resulting mutants}

Deletion mutation strains were constructed using the fusion PCR method illustrated previously [56]. Primers used for mutagenesis were listed in Additional file 1. In brief, two DNA fragments flanking the target gene were generated from $S$. oneidensis genomic DNA by PCR with primers $5 F / 5 R$ and $3 F / 3 R$, respectively. Fusion PCR was then performed to join these two DNA fragments with primers $5 \mathrm{~F} / 3 \mathrm{R}$. The resulting single fragment was digested with SacI and ligated into the SacI-digested and phosphatase-treated suicide vector pDS3.0. The resultant vectors were electroporated into the donor strain, E. coli WM3064 and then moved to S. oneidensis by conjugation. Integration of the mutagenesis construct into the chromosome and resolution were performed to generate the final deletion strains. The deletion was verified by PCR and DNA sequencing.

For complementation, DNA fragments containing aggA or $f l g A$ were generated by PCR amplification with MR-1 genomic DNA as the template using primers SO4320-COM-F/SO3988-COM-R and SO3253-COM-F/ SO3253-COM-R, respectively as listed in Additional file 1. These fragments were digested with $S a c I$ and ligated to SacI-digested pBBR1MCS-5 to form pBBR-AGGA and pBBR-FLGA, which was electroporated into WM3064. Introduction of pBBR-AGGA or pBBR-FLGA into the corresponding mutant was done by conjugation, and gentamycin-resistant colonies were selected. The presence of pBBR-AGGA or pBBR-FLGA in the corresponding mutant was confirmed by plasmid purification and restriction enzyme digestion.

\section{Swarm and swimming motility assay}

A fresh colony of tested strains was grown to an $\mathrm{OD}_{600}$ of 0.8 in LB media. The cultures $(1 \mathrm{ml})$ were spotted onto a swarm LB plate $(0.5 \%$ agar $)$ or stabbed into a swimming LB plate ( $0.2 \%$ agar). All plates were incubated at the room temperature for $48 \mathrm{~h}$. Images were acquired using Alpha Innotech's Fluorchem imaging system.

\section{SSA biofilm assay}

The SSA biofilm formation assay used is based on the method previously reported [57]. In brief, $3 \mathrm{ml}$ of fresh LB in $15 \mathrm{ml}$ glass tubes were inoculated with $S$. oneidensis strains from an overnight culture in LB at $200 \mathrm{rpm}$. 
After 16, 24, 32, or $40 \mathrm{~h}$ of incubation at $200 \mathrm{rpm}$ at room temperature, $500 \mu \mathrm{l}$ of $1 \%(\mathrm{wt} / \mathrm{vol})$ crystal violet (CV) solution was added to each tube and incubated for $15 \mathrm{~min}$. Tubes were rinsed three times with $5 \mathrm{ml}$ of distilled $\mathrm{H}_{2} \mathrm{O}$ and air dried. Biofilm formation was quantified by measuring the absorbance at $575 \mathrm{~nm}$. Each assay was performed four times.

\section{Thin layer chromatography (TLC) analysis}

Supernatants and pellicles were collected after $36 \mathrm{~h}$ of growth in static LB media. Pellicles were treated with $100 \mu \mathrm{g} / \mathrm{mL}$ proteinase $\mathrm{K}$ for removal of cells. Cell-less pellicles and supernatants were subjected to exopolysaccharide extraction and hydrolysis with trifluoroacetic acid as described previously [58]. The resulting monosaccharides were dissolved in $d_{d H_{2}} \mathrm{O}$ in the concentration of $10 \mathrm{mg} / \mathrm{ml}$, and $2 \mu \mathrm{l}$ of the sample was spotted onto TLC plates (silica gel $60 \mathrm{~F}_{254}$; Merck). After development in butan-1-ol-acetone-water (4:5:1), the TLC plates were dipped in the reagent aniline-diphenylamine in acetone and incubated for 2 to $5 \mathrm{~min}$ at $100^{\circ} \mathrm{C}$.

\section{Additional material}

Additional file 1: Primers used in this study. File contains all primers used in this study

\begin{abstract}
Acknowledgements
This research was supported by Major State Basic Research Development Program (973 Program: 2010CB833803) and National Natural Science Foundation of China (30870032) to HG. This research was also supported by Chinese Science Foundation for Distinguished Group (No.50321402) to YL. This research was also supported by The U.S. Department of Energy under the Genomics: GTL Program through Shewanella Federation, Office of Biological and Environmental Research, Office of Science.

\section{Author details}

${ }^{1}$ School of Minerals processing and Bioengineering, Central south University, Changsha, 410083, PR China. ${ }^{2}$ Institute for Environmental Genomics and Department of Botany and Microbiology, University of Oklahoma, Norman, 73019, USA. ${ }^{3}$ Institute of Microbiology and College of Life Sciences, Zhejiang University, Hangzhou, Zhejiang 310058, PR China.
\end{abstract}

\section{Authors' contributions \\ $Y L$ carried out pellicle formation and characterization experiments and drafted the manuscript. HG conceived of the study, and participated in its design, and directed all experiments and coordination and drafted the manuscript. JC carried out the mutagenesis experiments. YD and LW carried out SSA biofilm and TLC assays. ZH participated in design of the study and helped to draft the manuscript. $X L$ and GQ participated in the design of the study and helped to draft the manuscript. JZ conceived of the study, and participated in its design and coordination and helped to draft the manuscript. All authors read and approved the final manuscript.}

Received: 29 May 2010 Accepted: 16 November 2010 Published: 16 November 2010

\section{References}

1. O'Toole G, Kaplan HB, Kolter R: Biofilm formation as microbial development. Ann Rev Microbiol 2000, 54:49-79.
2. Watnick P, Kolter R: Biofilm, city of microbes. J Bacteriol 2000, 182:2675-2679.

3. Stoodley P, Sauer K, Davies DG, Costerton JW: Biofilms as complex differentiated communities. Ann Rev Microbiol 2002, 56:187-209.

4. Kolter R, Greenberg EP: Microbial sciences-The superficial life of microbes. Nature 2006, 441:300-302.

5. Goller CC, Romeo T: Environmental Influences on Biofilm Development. In Bacterial Biofilms 2008, 37-66.

6. Spormann AM: Physiology of microbes in biofilms. In Bacterial Biofilms 2008, 17-36

7. Karatan E, Watnick P: Signals, Regulatory Networks, and Materials That Build and Break Bacterial Biofilms. Microbiol Mol Biol Rev 2009, 73:310-347.

8. Liu M, Alice AF, Naka H, Crosa JH: HlyU protein is a positive regulator of rtxA1, a gene responsible for cytotoxicity and virulence in the human pathogen Vibrio vulnificus. Infect Immun 2007, 75:3282-3289.

9. Rainey PB, Travisano M: Adaptive radiation in a heterogeneous environment. Nature 1998, 394:69-72.

10. Ude S, Arnold DL, Moon CD, Timms-Wilson T, Spiers AJ: Biofilm formation and cellulose expression among diverse environmental Pseudomonas isolates. Environ Microbiol 2006, 8:1997-2011.

11. Lemon KP, Earl AM, Vlamakis HC, Aguilar C, Kolter R: Biofilm development with an emphasis on Bacillus subtilis. In Bacterial Biofilms 2008, 1-16.

12. Enos-Berlage JL, Guvener ZT, Keenan CE, McCarter LL: Genetic determinants of biofilm development of opaque and translucent Vibrio parahaemolyticus. Mol Microbiol 2005, 55:1160-1182.

13. Joshua GWP, Guthrie-Irons C, Karlyshev AV, Wren BW: Biofilm formation in Campylobacter jejuni. Microbiology 2006, 152:387-396.

14. Houry A, Briandet R, Aymerich S, Gohar M: Involvement of motility and flagella in Bacillus cereus biofilm formation. Microbiology 2010, 156:1009-1018.

15. Deighton M, Borland R: Regulation of slime production in Staphylococcus epidermidis by iron limitation. Infect Immun 1993, 61:4473-4479.

16. Moelling C, Oberschlacke R, Ward P, Karijolich J, Borisova K, Bjelos N, Bergeron B: Metal-dependent repression of siderophore and biofilm formation in Actinomyces naeslundii. FEMS Microbiol Lett 2007, 275:214-220.

17. Kobayashi K: Bacillus subtilis pellicle formation proceeds through genetically defined morphological changes. J Bacteriol 2007, 189:4920-4931

18. Solano C, Garcia B, Valle J, Berasain C, Ghigo JM, Gamazo C, Lasa I: Genetic analysis of Salmonella enteritidis biofilm formation: critical role of cellulose. Mol Microbiol 2002, 43:793-808.

19. Spiers AJ, Bohannon J, Gehrig SM, Rainey PB: Biofilm formation at the air-liquid interface by the Pseudomonas fluorescens SBW25 wrinkly spreader requires an acetylated form of cellulose. Mol Microbiol 2003, 50:15-27.

20. Bagge D, Hjelm M, Johansen C, Huber I, Grami L: Shewanella putrefaciens adhesion and biofilm formation on food processing surfaces. Appl Environ Microbiol 2001, 67:2319-2325.

21. De Vriendt K, Theunissen S, Carpentier W, De Smet L, Devreese B, Van Beeumen J: Proteomics of Shewanella oneidensis MR-1 biofilm reveals differentially expressed proteins, including AggA and RibB. Proteomic 2005, 5:1308-1316.

22. De Windt W, Gao H, Kromer W, Van Damme P, Dick J, Mast J, Boon N, Zhou J, Verstraete W: AggA is required for aggregation and increased biofilm formation of a hyper-aggregating mutant of Shewanella oneidensis MR-1. Microbiology 2006, 152:721-729.

23. Teal TK, Lies DP, Wold BJ, Newman DK: Spatiometabolic stratification of Shewanella oneidensis biofilms. Appl Environ Microbiol 2006, 72:7324-7330.

24. Thormann KM, Saville RM, Shukla S, Pelletier DA, Spormann AM: Initial phases of biofilm formation in Shewanella oneidensis MR-1. J Bacteriol 2004, 186:8096-8104

25. Thormann KM, Saville RM, Shukla S, Spormann AM: Induction of rapid detachment in Shewanella oneidensis MR-1 biofilms. J Bacteriol 2005, 187:1014-1021.

26. Thormann KM, Duttler S, Saville RM, Hyodo M, Shukla S, Hayakawa Y, Spormann AM: Control of formation and cellular detachment from Shewanella oneidensis MR-1 biofilms by cyclic di-GMP. J Bacteriol 2006, 188:2681-2691.

27. Walters MC, Roe F, Bugnicourt A, Franklin MJ, Stewart PS: Contributions of Antibiotic penetration, oxygen limitation, and low metabolic activity to 
tolerance of Pseudomonas aeruginosa biofilms to ciprofloxacin and tobramycin. Antimicrob Agents Chemother 2003, 47:317-323.

28. Kite P, Eastwood K, Sugden S, Percival SL: Use of In Vivo-generated biofilms from hemodialysis catheters to test the efficacy of a novel antimicrobial catheter lock for biofilm eradication In Vitro. J Clin Microbio 2004, 42:3073-3076.

29. Banin E, Brady KM, Greenberg EP: Chelator-induced dispersal and killing of Pseudomonas aeruginosa cells in a biofilm. Appl Environ Microbiol 2006, 72:2064-2069.

30. Pratt LA, Kolter R: Genetic analysis of Escherichia coli biofilm formation: roles of flagella, motility, chemotaxis and type I pili. Mol Microbiol 1998, 30:285-293.

31. Lemon $K P$, Higgins $D E$, Kolter R: Flagellar motility is critical for Listeria monocytogenes biofilm formation. J Bacteriol 2007, 189:4418-4424.

32. Merritt PM, Danhorn T, Fuqua C: Motility and chemotaxis in Agrobacterium tumefaciens surface attachment and biofilm formation. $J$ Bacteriol 2007, 189:8005-8014.

33. Parsek MR, Tolker-Nielsen T: Pattern formation in Pseudomonas aeruginosa biofilms. Curr Opin Microbiol 2008, 11:560-566.

34. Nambu T, Kutsukake K: The Salmonella FlgA protein, a putative periplasmic chaperone essential for flagellar $\mathrm{P}$ ring formation. Microbiology 2000, 146:1171-1178.

35. Theunissen S, Vergauwen B, De Smet L, Van Beeumen J, Van Gelder P Savvides SN: The agglutination protein AggA from Shewanella oneidensis MR-1 is a TolC-like protein and forms active channels in vitro. Biochem Biophys Res Commun 2009, 386:380-385.

36. Whitchurch CB, Tolker-Nielsen T, Ragas PC, Mattick JS: Extracellular DNA required for bacterial biofilm formation. Science 2002, 295:1487-1487.

37. Branda SS, Vik A, Friedman L, Kolter R: Biofilms: the matrix revisited. Trends Microbiol 2005, 13:20-26.

38. McLean JS, Pinchuk GE, Geydebrekht OV, Bilskis CL, Zakrajsek BA, Hill EA Saffarini DA, Romine MF, Gorby YA, Fredrickson JK, Beliaev AS: Oxygendependent autoaggregation in Shewanella oneidensis MR-1. Environ Microbiol 2008, 10:1861-1876.

39. Teitzel GM, Parsek MR: Heavy metal resistance of biofilm and planktonic Pseudomonas aeruginosa. Appl Environ Microbiol 2003, 69:2313-2320.

40. Priester JH, Olson SG, Webb SM, Neu MP, Hersman LE, Holden PA: Enhanced exopolymer production and chromium stabilization in Pseudomonas putida unsaturated biofilms. Appl Environ Microbiol 2006, 72:1988-1996.

41. Harrison JJ, Ceri H, Turner RJ: Multimetal resistance and tolerance in microbial biofilms. Nature Rev Microbiol 2007, 5:928-938.

42. Turakhia MH, Characklis WG: Activity of Pseudomonas aeruginosa in biofilms-effect of calcium. Biotechnol Bioeng 1989, 33:406-414.

43. Huang J, Pinder KL: Effects of calcium on development of anaerobic acidogenic biofilms. Biotechnol Bioeng 1995, 45:212-218.

44. Kierek K, Watnick PI: The Vibrio cholerae 01390-antigen polysaccharide is essential for Ca2+-dependent biofilm development in sea water. Proc Natl Acad Sci USA 2003, 100:14357-14362.

45. Singh PK, Parsek MR, Greenberg EP, Welsh MJ: A component of innate immunity prevents bacterial biofilm development. Nature 2002, 417:552-555.

46. Chen X, Stewart PS: Role of electrostatic interactions in cohesion of bacterial biofilms. Appl Microbiol Biotechnol 2002, 59:718-720.

47. Berlutti F, Morea C, Battistoni A, Sarli S, Cipriani P, Superti F, Ammendolia MG, Valenti P: Iron availability influences aggregation, biofilm, adhesion and invasion of Pseudomonas aeruginosa and Burkholderia cenocepacia. Inter Journal Immunopath Ph 2005, 18:661-670.

48. Tomaras AP, Dorsey CW, Edelmann RE, Actis LA: Attachment to and biofilm formation on abiotic surfaces by Acinetobacter baumannii: involvement of a novel chaperone-usher pili assembly system. Microbiology 2003, 149:3473-3484

49. Johnson M, Cockayne A, Williams PH, Morrissey JA: Iron-responsive regulation of biofilm formation in Staphylococcus aureus involves furdependent and fur-independent mechanisms. J Bacteriol 2005, 187:8211-8215.

50. Tart AH, Wozniak DJ: Shifting paradigms in Pseudomonas aeruginosa biofilm research. In Bacterial Biofilms 2008, 193-206.

51. Spoering AL, Gilmore MS: Quorum sensing and DNA release in bacterial biofilms. Curr Opin Microbiol 2006, 9:133-137.
52. Lappann M, Claus H, Van Alen T, Harmsen M, Elias J, Molin S, Vogel U: A dual role of extracellular DNA during biofilm formation of Neisseria meningitidis. Mol Microbiol 2010, 75:1355-1371.

53. Saltikov CW, Newman DK: Genetic identification of a respiratory arsenate reductase. Proc Natl Acad Sci USA 2003, 100:10983-10988.

54. Gao H, Wang XH, Yang ZK, Palzkill T, Zhou JZ: Probing regulon of ArcA in Shewanella oneidensis MR-I by integrated genomic analyses. BMC Genomics 2008, 9:42.

55. Yap MN, Rojas $\mathrm{CM}$, Yang $\mathrm{CH}$, Charkowski AO: Harpin mediates cell aggregation in Erwinia chrysanthemi 3937. J Bacteriol 2006, 188:2280-2284.

56. Gao WM, Liu YQ, Giometti CS, Tollaksen SL, Khare T, Wu LY, Klingeman DM, Fields MW, Zhou J: Knock-out of S01377 gene, which encodes the member of a conserved hypothetical bacterial protein family COG2268, results in alteration of iron metabolism, increased spontaneous mutation and hydrogen peroxide sensitivity in Shewanella oneidensis MR-1. BMC Genomics 2006, 7:76.

57. O'Toole GA, Kilter R: Flagellar and twitching motility are necessary for Pseudomonas aeruginosa biofilm development. Mol Microbiol 1998, 30:295-304.

58. Wall P: Thin layer Chromatography: A modern practical approach RSC publishing; 2005.

doi:10.1186/1471-2180-10-291

Cite this article as: Liang et al:: Pellicle formation in Shewanella oneidensis. BMC Microbiology 2010 10:291.

\section{Submit your next manuscript to BioMed Central and take full advantage of:}

- Convenient online submission

- Thorough peer review

- No space constraints or color figure charges

- Immediate publication on acceptance

- Inclusion in PubMed, CAS, Scopus and Google Scholar

- Research which is freely available for redistribution 